\title{
ANALYSIS OF THE EVOLUTION OF THE TRANSPORT FLEET AT EU LEVEL
}

\author{
Florin DOBRE ${ }^{* a}$, Amza MAIR ${ }^{b}$, Alexandru VASILESCU ${ }^{c}$, Anna KANT ${ }^{d}$ \\ ${ }^{a}$ Bucharest University of Economic Studies, Romania \\ b, Valahia University of Târgoviște, Romania \\ ${ }^{d}$ Politehnic Bucharest University, Romania
}

\begin{abstract}
The general transport network in the European Union is of particular importance, especially given the operation of the two directives on the free movement of goods and services within the European Community. Transport is a strategic sector of the EU economy, which directly affects the daily lives of all EU citizens. Transportation services provide about 11 million jobs. They are a cornerstone of European integration, with fully interconnected and sustainable transport networks being a necessary condition for the completion and proper functioning of the European single market.

The transport of goods and goods is carried out by road, rail, sea and air. Each of these transport routes has particularities that are suitable, depending on the group of goods, for the movement of goods. The European Union has adopted its own strategy aimed at developing and harmonizing the transport network in each Member State, so as to achieve a single transport network at Union level. In this context, using the data provided by Eurostat, the authors carry out a detailed analysis of the perspective of transport developments in the European Union. The volume of passenger and freight transport in the EU has increased in recent decades and this trend is expected to continue, albeit at a slower pace. Transport is an area of shared EU competence, which means that Member States can exercise their own competence, unless the EU has formulated common transport policies and strategies.
\end{abstract}

KEYWORDS: development, ports, technology, transport

DOI: $10.24818 / I M C / 2021 / 02.18$

\section{INTRODUCTION}

The European Union pays particular attention to the infrastructure of the Member States, with an emphasis on the development of a road, rail network (Burlacu et al., 2013) and, of course, in this context, the number 1 issue is the development of uniform, high-quality infrastructure in all EU Member States (Beall, 2017).

New technologies have been introduced in the shipbuilding industry, among which the concept of the Internet of Things and the Internet of Ships will be presented. In the supply chain, passive data is transformed into the target intelligence of the business. This improves the commands received, accuracy, overall performance and predictability (Markus, 2019).

With the development of science and technology, traffic perception, communication, information processing, artificial intelligence and the maritime information system have become important in supporting its realization (Burlacu \& Stoica, 2012), which is why the Internet of Ships

(IoV) is proposed to integrate all these advanced technologies into a platform that meets the requirements of international and regional transport (Kapidani, 2020).

\footnotetext{
* Corresponding author. E-mail address: florin.dobre@cig.ase.ro
} 
The aim is to look at how to benefit in order to improve the efficiency and safety of maritime transport and promote the development of transport (Bran et al., 2018). IoV is also introduced in ship architecture (Zhe, 2019).

Due to the development of technologies and travel, they can be improved in terms of maintenance and management (Litra \& Burlacu, 2014), which highlight the preventive mode when operations are interrupted, or can be economically improved to add value to artificial intelligence solutions (Bennett, 2019).

The industry is economically motivated, given that artificial intelligence (AI) acts as a technological bridge that links efficiency, financial and environmental results in connectivity.

IoT connectivity can turn day-to-day operations into logistics networks. This reduces problems such as downtime or streamlining processes, for example the port of Rotterdam where there is a continuous flow of ships in docks, cranes and containers. The terminal operates at full capacity, recording a productivity of containers by $25-50 \%$ more than any other competing port.

Artificial intelligence connects data and operations with proactive guidance to keep ships moving as much as possible using data from a chain of information connected to all external sources. It guides ship captains to make more profitable decisions based on weather conditions, loading time. of ports or congestion of routes (Kardakova, 2020).

Satellite connectivity uses satellites to connect equipment, systems, machines, or anything that contains a data transmitter (Macharis, K., 2019). For full service, companies will need connectivity to track and secure both goods and equipment. Shipowners who want to benefit from the operation of ships in a current way will need this technology of satellite connectivity and remote monitoring. The article aims to analyze the evolution of the transport fleet at EU level, a key factor in current and future economic development. In the methodology of this approach, the analysis of some principles related to this field was used, as well as the analysis of the specialized literature. At the same time, a comparison between several series of statistical data related to transport at European level was considered. Thus, as a novelty element proposed in this paper is the realization of an interdependent connection between globalization, technology and the maritime transport system.

\section{MANUSCRIPT}

\subsection{The evolution of maritime transport}

The main feature of maritime transport is the dynamics created around it regarding the development of trade, resources, economy and their realization (Anghelache, C., 2016).

Regarding the demand for maritime transport, the economic expansion is the most important and in 2019 the economy has grown compared to 2018. The main economic and transport indicators that reflect the increase in investment are the activity and trade of goods. At the same time, a number of risks continued to arise, which led to major implications for them. Due to the $3.1 \%$ expansion of GDP in 2019, compared to $2.5 \%$ in 2018 , the economy has generated positive effects on maritime trade.

Economic growth has evolved in the EU (2.4\%) being a significant evolution. Developing countries recorded economic growth of $4.5 \%$ compared to $3.9 \%$ in 2018 , reflecting incompatible activity in commodity exporting countries and a more favorable economic environment.

GDP growth of $4.3 \%$ in less developed countries has improved although it is still below the $7 \%$ growth target of the sustainable development targets.

High commodity prices provided a gain on exports of goods, which influenced import demand. Trade largely reflects the correlation between investment spending and capital. In Europe, exports were lower in 2018 (1.1\%), increasing significantly in 2019 (3.5\%) and imports registered in 2018 $(3.1 \%)$ were higher than in $2019(2.5 \%)$. 


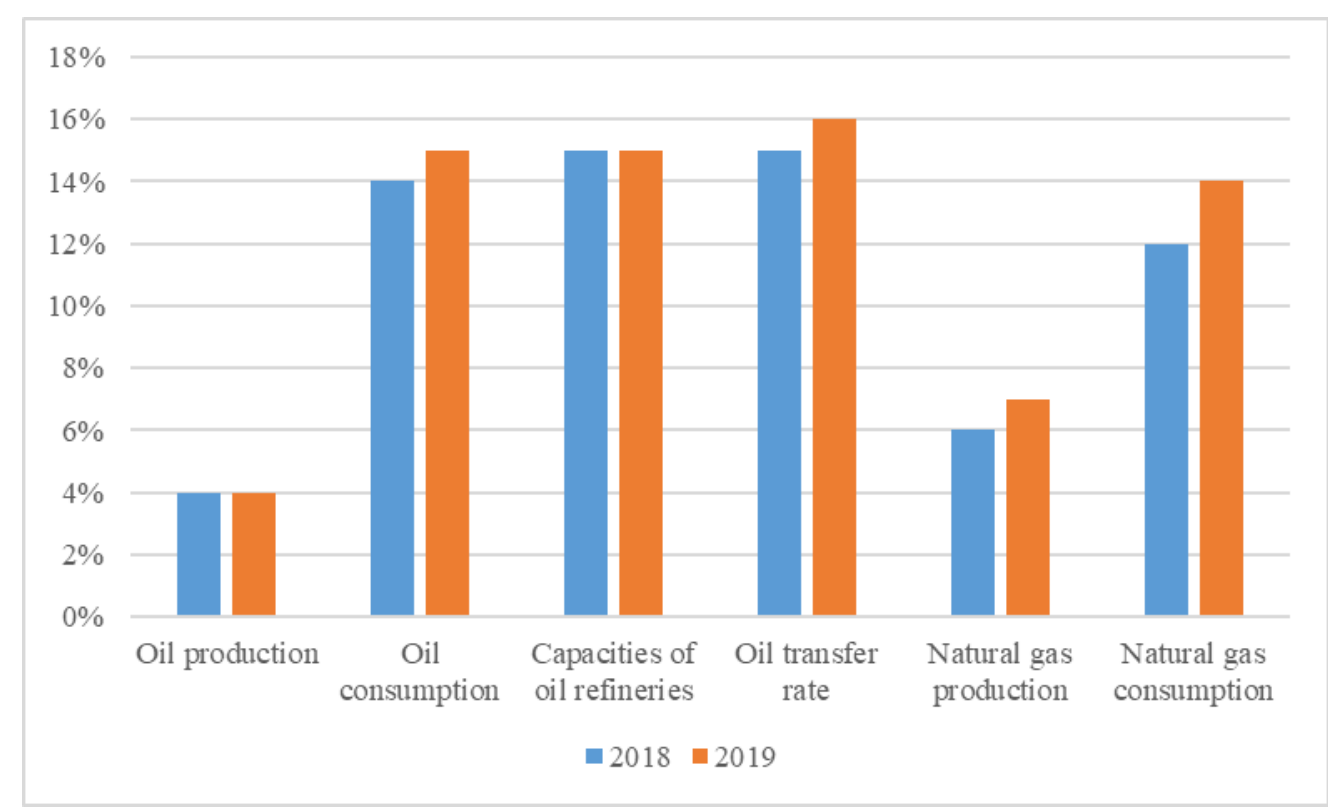

Figure 1- Major producers and consumers of oil and gas in Europe Source: Review maritime transport 2019

Figure 1 shows the production and consumption of oil and natural gas in Europe in 2018 and 2019. Oil production remained unchanged at $4 \%$, while consumption increased from one year to another by $1 \%$. Figure 1 shows the production and consumption of oil and natural gas in Europe in 2018 and 2019. Oil production remained unchanged at $4 \%$, while consumption increased from one year to another by $1 \%$.

\subsection{Fleet structure and registration}

The shipbuilding industry is investing heavily in technologies that have the potential to change the way ships are operated, to automated navigation and cargo tracking systems (Agnieszka, 2019). They can reduce costs and increase the supply chain.

Technological developments can contribute to the management of optimized assets and operations, for example in the provision of data on fuel, consumption and performance (Bartholdi, 2016). Such systems allow the identification and monitoring of the ship or other issues that may be important in maneuvering or establishing the route.

\begin{tabular}{|c|c|c|}
\hline Country & 2018 & 2019 \\
\hline Greece & 728 & 4.199 \\
\hline Germany & 240 & 3.090 \\
\hline Denmark & 398 & 920 \\
\hline Belgium & 93 & 263 \\
\hline Italy & 575 & 768 \\
\hline France & 179 & 452 \\
\hline Cyprus & 128 & 277 \\
\hline
\end{tabular}

Source: Review maritime transport, 2019 
Table 1 lists some of the EU member states that have fleets. Compared to 2018 with 728, 2019 was a productive year for Greece, because 4.199 ships are registered.

The lowest registration in 2018 and 2019 was in Belgium. The maritime merchant fleet grew by $3.15 \%$ in 2018 , compared to $3.5 \%$ in 2015 . Despite this decline, supply grew faster than demand, leading to a continuing situation of overcapacity and downward pressure on transport tariffs.

Greece registered 21 million dwt in the container ship market in 2019, now it has a market share of $17.3 \%$ followed by Germany with $5.6 \%$. And the market share of oil tankers is $24 \%$. Shipowners in Greece prefer to buy bulk carriers and oil tankers, as they have a large transport capacity. Among those who do not deal with line services and resort to renting them, Germany has a market share of one third.

Table 2- Ranking of shipowners according to deadweight tonnage

\begin{tabular}{|l|l|l|}
\multicolumn{1}{|c|}{ Country } & \multicolumn{1}{c|}{2018} & \multicolumn{1}{c|}{2019} \\
\hline Greece & $308.836,933$ & $330.176,000$ \\
\hline Germany & $112.028,306$ & $107.119,000$ \\
\hline Denmark & $36.355,509$ & $39.212,000$ \\
\hline Belgium & $23.550,024$ & $23.630,000$ \\
\hline Italy & $20.609,725$ & $19.750,000$ \\
\hline France & $11.931,397$ & $12.141,000$ \\
\hline Cyprus & $9.257,094$ & $10.229,000$ \\
\hline
\end{tabular}

Source: Review Maritime Transport 2018-2019

Orders in Europe have been in a slight decline, but in the last three years, it has been well above any of the other shipbuilding regions, due to the large increase in orders for cruise ships (Pallis, A. A. 2017).

The average construction price increased by 5\% since April 2019. The largest increase in prices took place in the bulk ship segment, followed by the container and tanker segments.

Given that the price of natural gas continued to fall, a stronger demand was determined, the prices of raw materials increased, which caused the profitability of the sites.

The EU maritime fleet is experiencing continuous growth in the period 2018-2019, thus doubling its capacity due to the increase in maritime transport services. One feature of the fleet is the price of new vessels, which increases depending on the type of vessel. So the shipbuilding market is fluctuating in terms of prices.

\subsubsection{The maritime market}

In 2018 and early 2019, the maritime industry registered a significant improvement in most markets, except for the oil market. The container transport industry ended in 2019, with a total profit of about $\$ 7$ billion, mainly due to a significant increase in transport tariffs.

During the year, consolidation in the form of procurement, persisted in the container industry and were in response to the negative environment facing the industry in recent years. When there were no direct negative effects on trade and costs, there were concerns about the ever-growing competitive market.

In 2019, the bulk goods market registered a remarkable growth, which translated into clear gains for carriers, thus compensating for the depreciated revenues from 2018. Among the EU Member States, the largest quantities of goods transported were registered in partnership with Spain (810 thousand tons) and Greece (573 thousand tons). The Netherlands, Spain and Italy registered in 2019, 50.4\% of the total volume of port loading and unloading and Romania only $1 \%$. 


\subsection{Management of seaports}

Seaports are very important from an economic point of view for the European Union. There are more than 1,200 commercial seaports in 22 of the 27 EU Member States. They are the main nodes of the trade network, as they handle about three quarters of goods traded between the EU and third countries and more than a third of goods transported within the EU.

In an attempt to reduce costs and increase operational efficiency, ship sizes for all segments (oil tankers, container vessels) have been steadily increasing in recent years.

The use of larger ships requires new infrastructure and also affects competition between port authorities and port operators, and reduces shipping costs and accounts for a quarter of the ship's size.

This competition between ports has led to the specialization of terminals and sometimes to the excessive adaptation to the requirements of modern logistics chains of maritime transport, involving strong changes in port operations (Göçmen, E., 2018).

However, the increase in the size of ships is, at least in the main European ports, one of the factors contributing to the need for additional capacity and new port infrastructure and superstructures.

In addition to the need to make specific investments to adapt ports, very large ships create challenges such as: the much larger volume of cargo transported leads to peak periods in port activity and creates the risk of congestion in port areas (Grzelakowski, A. S., 2011).

These ships increase the risk that investments in port infrastructure will not be sustainable, as a significant number of containers and significant volumes of cargo can be transferred from one port to another, thus putting increased pressure on ports to offers attractive landing rates. Member States should adopt a sound and coherent long-term strategy for their development. Identifying quality elements helps stakeholders to include them in port development policies.

Due to the particularities of each port, the implementation of these quality components depends on the port and terminal. Port services are not limited to the port area and must be integrated into the supply chain (Iris, Ç., 2019). With the automation and digitization of activities in the port area, customer requirements have diversified, and the correlation of quality processes requires changes to maintain competitiveness. Investments in port infrastructure need some time to produce results.

Strategic line shipping alliances and chartering have made the relationship between container transport and ports more complex, thus triggering a new dynamic, whereby shipping lines have a stronger bargaining influence. Important areas include, the selection of ports of call, the configuration of maritime transport networks, the distribution of costs and benefits between container transport and ports.

Improving the performance of ports and terminals in all segmented markets is increasingly recognized as essential for planning, investment and strategic positioning, as well as for meeting sustainability criteria and sustainable development objectives. Ports, operators and users should work together to identify and improve port productivity, cost-effectiveness and operational efficiency.

\subsection{Freight transport in Romanian ports}

The presence of ports on the Black Sea coast and on the Danube ensures the development of maritime transport. The ports of Constanţa, Midia and Galaţi, register both maritime transport activity and inland waterway transport activity. Increases of maritime and inland waterway transport indicators totaled 11,040 thousand tons, and container transport amounted to 160 thousand TEU, during the first quarter of 2018.

During the same period, 5.548 thousand tons of goods were transported by inland waterways and respectively $328 \mathrm{TEU}$ and values of 2.433 million $\mathrm{t} / \mathrm{km}$, respectively 275 thousand TEU / $\mathrm{km}$ were registered. Transport in ports increased by $16.5 \%$ compared to 2019 , due to the increase in the volume of unloaded goods by $30.3 \%$ and goods loaded by $4 \%$. 
The total volume in domestic transport and inland waterway transit increased by $42.2 \%$ and $35.4 \%$, respectively, while international transport decreased by $12.5 \%$ in 2018 compared to 2019 . The ports where the highest volumes of goods were registered are: Constanţa, with a share of $77 \%$, Midia (20\%) and Galaţi (3\%) (see figure 2).

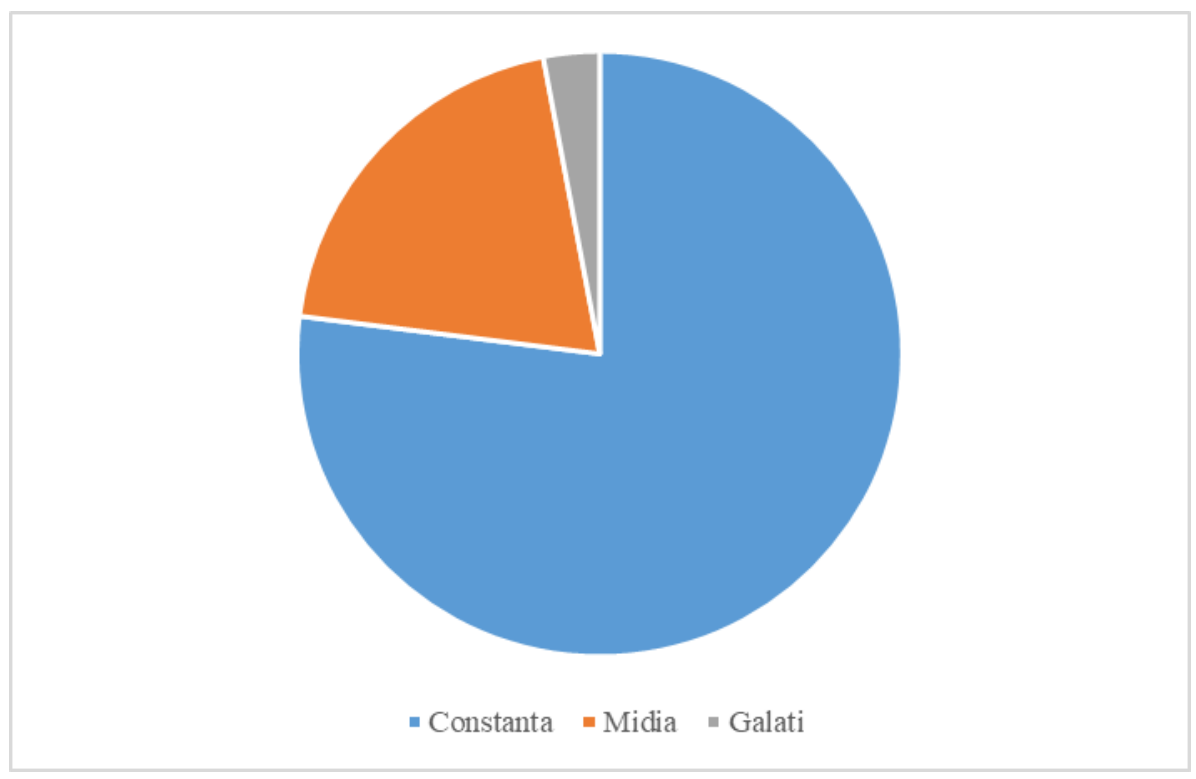

Figure 2- The volume of goods

Source: INSSE, 2019

Bulk solid goods were transported, with a share of $47.1 \%$ in the total goods loaded and unloaded. The same type of goods dominated shipments (58\%), while bulk liquid goods - unloadings (47.9\%). Romania is on the fourth place, $6.9 \% \mathrm{t} / \mathrm{km}$, in 2019, among the member states regarding the volume of inland waterway transport. From the point of view of the volume of goods transported by inland waterways expressed in tons, Romania ranked fifth.

\section{CONCLUSIONS}

New technologies represent a new infrastructure that has been created through the widespread use of digital communications and information.

Information resources are perceived as including information technologies themselves. The differences from traditional resources are that information is replaced and transportable.

In addition to modern ships already built or to be built, port systems are being developed and modernized in which specialized and high-productivity terminals are set up based on the latest transport and handling technologies.

The technology transforms ports using a complex range of sensors to collect data on tidal flows, wind power and visibility, helping to reduce ship waiting times and automatic unmanned berth guidance. But ports and terminals need to re-evaluate their logistical role and prepare to learn about digitalisation, innovation and technology, which have significant transformation potential.

Digitization results in price transparency and ship performance so competition increases. The price of the freight may be reduced over time but not for second-hand ships. In the field of construction of the container industry, the aim is to integrate the supply chain from shipper to consignee and not from port to port. Those who want digitization have plans to implement more parts of their ecosystem by starting to provide additional services. 
In the second part of the paper we addressed the performance of the transport activity that followed the line of EU economic development and freight transport, the evolution in structure and dynamics in the period 2018-2019 that was given by maritime transport.

The diversification of goods and the demand for products took place with the development of the economy and trade, led to the diversification and specialization of ships, which in turn led to the development of specialized ports and terminals. The size of the ships and the time the ships arrive at the terminal are the most important elements.

Along with the economy, maritime transport also developed, knowing both the ascending and descending slopes of trade. Maritime transport is represented by a well-established international community, which uses advanced communication systems or high-performance fleets, enjoying the fundamental principle of increased trade. Improving the performance of ports and terminals in all segmented markets is increasingly recognized as essential for planning, investment and strategic positioning, as well as for meeting sustainability criteria and sustainable development objectives.

Connectivity and artificial intelligence optimize decision-making and allow strategies to be evaluated alternately. It can also be represented by the maritime industry which is the best index for the economy or the optimization capacity that allows the industry to adjust the supply according to the demand. The use of larger ships reduces shipping costs. The use of larger ships requires new infrastructure and also affects competition between port authorities and port operators.

Increasing the size of ships is, at least in European ports, one of the main factors contributing to the need for additional capacity and new port infrastructure and superstructures. In addition to the need to make specific investments to adapt ports, very large ships create other challenges for them: the much larger volume of cargo transported leads to peak periods in port activity and creates the risk of congestion of port areas and connections. transport with the economic hinterlands.

\section{ACKNOWLEDGMENT}

Thanks to the team for their help in writing this article. I would like to thank the National Institute of Statistics for their assistance with the statistics used in this report. I would like to express my deep gratitude to my colleagues for their continued encouragement, critical analysis of this article, and guidance.

\section{REFERENCES}

Agnieszka, T., \& Sylwia, W. 2019. Risk assessment issues in the process of freight transport performance, Wroclaw University of Science and Technology,

Anghelache, C., Manole, A., Niţă, G., \& Stanciu, E. (2016). Significant Aspects regarding the Evolution of Economic Activity in Constructions and Transports, Romanian Statistical Review Supplement, 5, 85-95.

Bartholdi, J. J., Jarumaneeroj, P., \& Ramudhin, A. (2016). A new connectivity index for container ports. Maritime Economics and Logistics, 18(3), 231-249.

Beall, J. (2017). The European maritime transport policy with respect to sustainable development issues and climate commitments. Official Gazette of the French Republic

Bennett, N. J., Cisneros-Montemayor, A. M. et al. (2019). Towards a sustainable and equitable blue economy. Nat. Sustain., 2, 991-993

Bran, F., Burlacu, S., \& Alpopi, C. (2018). Urban Transport of Passengers in Large Urban Agglomerations and Sustainable Development. Experience of Bucharest Municipality in Romania. European Journal of Sustainable Development, 7(3), 265-273.

Burlacu, S., \& Stoica, A. (2012). Analysis of freight transport on the street network of Bucharest. Quality-Access to Success, 13.

Burlacu, S., \& Stoica, A. (2012). Modern public transport. Quality-Access to Success, 13. 
Burlacu, S., Stoica, A., Georgescu, B. C., \& Stoica, S. A. (2013c). Basarab overpass influence on road traffic in the Bucharest central area. main ring closure can come true or is a utopia?. In Proceedings of Administration and Public Management International Conference (Vol. 9, No. 1, pp. 182-190). Research Centre in Public Administration and Public Services, Bucharest, Romania.

Göçmen, E., \& Erol, R. (2018). The problem of sustainable intermodal transportation: A case study of an international logistics company, Turkey. Sustainability, 10, 4268

Grzelakowski, A. S. (2011). Internalization of external costs in the EU transport sector as an instrument of rationalization of the logistics supply chains. Logistics and Transport, 13(2), 57-67

Iris, Ç., \& Lam, J. (2019), A review of energy efficiency in ports: Operational strategies, technologies and energy management systems. Renew. Sust. Energ. Rev.112, 170-182

Kapidani, N., Bauk, S., \& Davidson, I. (2020). Digitalization in Developing Maritime Business Environments towards Ensuring Sustainability. Sustainability, 12, 9235

Kardakova M., Shipunov I., Nyrkov A., \& Knysh T. (2020). Cyber Security on Sea Transport Advances, Intelligent Systems and Computing, vol. 982, pp. 481-490

Litra, M., \& Burlacu, S. (2014). Management regulatory liberalization of the public service contracts in the rail industry. Administratie si Management Public, (22), 73.

Macharis, K., \& Nocera, S. (2019). The future of freight transport. European Transport Research Review, 11(1), 21.

Markus F., \& Frank T. (2019), Digitization in maritime logistics- What is there and what is missing?, Germany Osnabrueck University

Pallis, A. A. (2017). The common EU maritime transport policy: Policy Europeanisation in the 1990s. London: Routledge.

Zhe, T., Fushun, L., Zhixiong L., Reza, M., \& Yingchun X. (2019). The Development of Key Technologies in Applications of Vessels Connected to the Internet, Ocean University of China; Iowa State University,USA 